\title{
The prevalence of hypertension and associated risk factors in a Latino subgroup: A rural Batey population in the Dominican Republic
}

\author{
Gary Hon-chung Ho ${ }^{1}$, Anne Kate Press ${ }^{1}$, Christine Bumatay Sethna ${ }^{1,2}$ \\ ${ }^{1}$ Hofstra North Shore-LIJ School of Medicine, Hempstead, US \\ ${ }^{2}$ Pediatric Nephrology, Cohen Children's Medical Center of New York, New Hyde Park, US
}

Email address:

gho1@pride.hofstra.edu (G. H. Ho), apress@yu.edu (A. K. Press), csethna@nshs.edu (C. B. Sethna)

To cite this article:

Gary Hon-chung Ho, Anne Kate Press, Christine Bumatay Sethna The Prevalence of Hypertension and Associated Risk Factors in a Latino Subgroup: A Rural Batey Population in the Dominican Republic. Science Journal of Public Health. Vol. 2, No. 5, 2014, pp. 480-485.

doi: $10.11648 /$ j.sjph.20140205.26

\begin{abstract}
Objective: To determine the prevalence of hypertension and identify variables associated with hypertension among residents of Batey 16. Methods: A cross-sectional study was conducted among adults residing in Batey 16 of La Romana, Dominican Republic. Residents were approached house to house and invited to participate in a blood pressure screening and a survey pertaining to risk factors for hypertension. Blood pressures and waist circumferences were measured. Comparisons between the hypertensive and non-hypertensive group's survey results, heights, and waist circumferences were made using chi square, Student's t-test or Mann-Whitney test, and univariate linear and logistic regression analysis. Results: Of the 187 participants, age $35 \pm 16$ years (range $18-107$ years), $34 \%$ were diagnosed with hypertension and $42 \%$ with were diagnosed with pre-hypertension. Age, sex, height, waist circumference, and use of medication were not significantly different between the hypertensive and the non-hypertensive participants. These variables in addition to elevated waist circumference were not associated with hypertension. Family history was an independent predictor of hypertension $(\mathrm{OR}=2.7$, $\mathrm{p}=0.013 ; 95 \% \mathrm{CI}, 1.2-5.8)$. Conclusions: The batey population has many unique characteristics that may contribute to its prevalence of hypertension and the patterns found in the associated risk factors. Further research needs to be conducted to broaden, explore, and clarify our findings.
\end{abstract}

Keywords: Hypertension, Batey, Dominican Republic, Haitian, Rural Population

\section{Introduction}

There exists numerous bateyes throughout the Dominican Republic, which house more than half a million residents [1]. The residents of bateyes comprise mostly of migrant Haitian laborers who work on the sugarcane plantations. Bateyes are characterized as isolated residential communities surrounded by sugarcane fields with no running water, no electricity, inadequate garbage disposal, and no medical facilities. In addition, the make-shift houses of wood and tin are often small and shelter multiple families [1-2]. Both the close quarters and lack of proper sanitation can lead to an increased risk of infection.

Furthermore, many characteristics of the agricultural worker population of the bateyes predispose them to inadequate healthcare access. The low wages of agricultural labor leaves these workers with limited economic resources [1]. The lack of immigration or citizenship documents limits this population's access to social services as well [2]. The migratory nature of many workers can result in a lack of continuity of care, a low socio-economic status, and the development of cultural barriers, especially in children [3]. The rural locations of bateyes conflict with the urban concentration of healthcare services by posing a physical barrier to access. Lastly, a language barrier inhibits communication between many Creole speaking Haitians and their Spanish speaking healthcare providers [2].

In a population with inadequate access to healthcare, hypertension is particularly a problem. Patients with hypertension are at an increased risk for cardiovascular morbidity and mortality from heart attack, aneurysm, blindness, kidney failure, and stroke [4]. Blood pressure cuffs are a simple, non-invasive way to measure arterial 
blood pressure and screen for hypertension. Unfortunately, lack of access to healthcare from poverty, migration, immigration, and lack of acculturation can impede routine blood pressure screening and treatment. Ultimately, this leads to underdiagnosed and uncontrolled hypertension.

While there is no literature that documents the prevalence of hypertension in the bateyes of the Dominican Republic, literature does support that the prevalence of hypertension in Haitians is markedly higher than in adults who reside in the region of the Americas [5-6]. Additionally, non-Hispanic blacks in the United States have higher rates of hypertension than other races and ethnicities in the United States [7] and Dominicans in the Dominican Republic [8]. Furthermore, living in a rural setting in lower or lower-middle income countries has been associated with less treatment, lower awareness, and less control of hypertension when compared to living in an urban setting in those same countries [9].

Based on the available data on hypertension in rural and Haitian communities as well as the characteristics of this unique population, we hypothesized that a high proportion of the population living in bateyes would be hypertensive and have multiple predisposing risk factors that increase their risk for hypertension. Therefore, the objective of this study was to determine the prevalence of hypertension in Batey 16 and to determine demographic and clinical variables associated with hypertension in this specific population.

\section{Methods}

A cross-sectional study of adults aged $\geq 18$ years residing in Batey 16 of La Romana, Dominican Republic was conducted. The primary outcome measure was the prevalence of hypertension and pre-hypertension in this population. Secondary outcome measures were variables that may predict an increased risk of hypertension. The North Shore-Long Island Jewish Health System Institutional Review Board approved this study, which took place from 2012-2013. Batey 16 was chosen as the study site because the Cohen Children's Medical Center of New York has a long-standing relationship with this community through their Batey Outreach Program.

\subsection{Study Design}

Prospective participants were approached individually at each house in Batey 16 and invited to participate in this study. There were approximately 110 households in total and all were visited. There were 1-4 families per household. All participants completed a survey, which asked about demographics, medications, medical conditions, dietary sodium intake, access to blood pressure screening, blood pressure status, and family history of hypertension. The survey instrument was not validated; however it was translated by a native Creole and Spanish speaker who is a healthcare professional. Translators administered the survey orally due to a high prevalence of illiteracy. During the visit, each participant's height, waist circumference, and blood pressure was measured.

\subsection{Instruments and Measurements}

After the initial survey, each participant's blood pressure was manually measured three consecutive times using a blood pressure cuff and a stethoscope. Blood pressures were measured on the right arm of participants whom were sitting down after rest. At least one minute was allowed in between consecutive measurements. Two healthcare personnel, whom were trained to manually measure blood pressure in a similar manner, performed the measurements. The average of the blood pressures was recorded. Participants were classified as normotensive if their systolic blood pressure was $<120 \mathrm{~mm} \mathrm{Hg}$ and diastolic blood pressure was $<80 \mathrm{~mm}$ Hg. Participants were classified as hypertensive if their systolic blood pressure was $\geq 140 \mathrm{~mm} \mathrm{Hg}$ and/or their diastolic pressure was $\geq 90 \mathrm{~mm} \mathrm{Hg}$. All participants who did not fit within these criteria were classified as pre-hypertensive.

Participant's waist circumferences and heights were measured using tape measures. The waist circumference was measured in centimeters at the level directly above the top of the iliac crest. An elevated waist circumference was defined as $>40$ inches $(101.6 \mathrm{~cm})$ in males and $>35$ inches $(88.9 \mathrm{~cm})$ in females. This classification was made according to the National Heart, Lung, and Blood Institute's waist circumference cutpoints for a high associated disease risk [10]. Height was measured in centimeters from the bottom of the heel to the peak of the skull.

\subsection{Educational Intervention}

Participants whom were classified as pre-hypertensive or hypertensive were given a brief educational intervention. Each of these participants was educated on the definition, symptoms, and consequences of hypertension. Pictorial handouts with minimal Spanish text were distributed to help explain the sequelae of long-standing hypertension and to remind participants of beneficial lifestyle modifications. In addition, a teaspoon was utilized as a visual representation of the recommended daily sodium intake.

\subsection{Statistical Analysis}

Statistical analyses were done using PASW 18 (SPSS Inc., Chicago, IL) statistical package. Descriptive statistics were used to characterize outcome measures in subjects and survey results. Means, standard deviations, 95\% confidence intervals, medians, and minimum and maximum values were tabulated and reported for all continuous variables. Frequency counts and percentages were used for categorical variables. To analyze the primary outcome, prevalence rates were determined for hypertension. Demographic and clinical variables were compared between hypertensive and non-hypertensive groups using chi square, Student's t-test or Mann-Whitney test. Associations between anthropometric variables and hypertension were evaluated by univariate linear and logistic regression analysis. 


\section{Results}

\subsection{Demographics}

The study sample consisted of 187 individuals, all of whom were residents of Batey 16. There were more participants who were male $(63 \%)$ than female $(37 \%)$. The mean age of the participants was $35 \pm 16$ years, with ages ranging from 18 to 107 years.

\subsection{Measurements}

Hypertension was prevalent in about one-third (34\%) of the study sample. A quarter of the study sample was normotensive (24\%) and just under half (42\%) was classified as pre-hypertensive. The mean systolic $(131 \pm 22$ $\mathrm{mm} \mathrm{Hg})$ and diastolic $(83 \pm 14 \mathrm{~mm} \mathrm{Hg})$ blood pressures were both within the pre-hypertensive range; the mean diastolic blood pressure was $\geq 80 \mathrm{~mm} \mathrm{Hg}$ and the mean systolic blood pressure was $\geq 120 \mathrm{~mm} \mathrm{Hg}$.

The waist circumference and height were measured in 99 of the study participants. The mean waist circumference in this group of participants was $83.8 \pm 14 \mathrm{~cm}$, with $17 \%$ having an elevated waist circumference.

\subsection{Survey Results}

Table 1 summarizes selected survey questions that were meant to assess possible variables associated with hypertension. About half of the study sample had their blood pressure measured within the last year $(45 \%)$, while most of the other half has never had their blood pressure measured (40\%). $25 \%$ of the study population reported previously being diagnosed with hypertension, however, only $8 \%$ of participants were taking blood pressure medication(s). Of the $8 \%$ of participants who were taking blood pressure medications, $60 \%$ had uncontrolled hypertension. Furthermore, out of the $25 \%$ of participants whom were previously diagnosed with hypertension, $40 \%$ still had hypertension. Based on the measured prevalence of hypertension, $30 \%$ of the hypertensive population was aware of their condition and only $47 \%$ of those who were aware of their hypertension were taking blood pressure medication(s) for it.

Table 1. Survey findings of possible risk factors for hypertension of adults in Batey $16(N=187)$

\begin{tabular}{ll}
\hline Findings & \% \\
\hline On any medications & 36 \\
On blood pressure medication(s) & 8 \\
Medical condition(s) & 40 \\
Diet high in sodium & 33 \\
Heard of the words 'hypertension' or 'high blood & 79 \\
pressure & 40 \\
Never had blood pressure measured & 45 \\
Had blood pressure measured within the last year & 25 \\
Have been diagnosed with hypertension & 51 \\
Family history of hypertension & \\
\hline
\end{tabular}

\subsection{Statistical Analysis}

Table 2 compares the hypertensive and non-hypertensive study populations' survey results and anthropometric measurements. The hypertensive group contained 63 individuals and the non-hypertensive group contained 124 individuals. Age, sex, height, and waist circumference were not significantly different between the hypertensive and the non-hypertensive participants. On the contrary, a family history positive for hypertension was significantly higher in the hypertensive group.

Table 2. Differences in characteristics of hypertensive and non-hypertensive groups

\begin{tabular}{lccc}
\hline Characteristic & No Hypertension & Hypertension & P-value \\
\hline Age (years) & $35.5 \pm 16.4$ & $34.6 \pm 14.7$ & 0.73 \\
Male (\%) & 64 & 62 & 0.80 \\
Height (cm) & $165.1 \pm 8.9$ & $163.1 \pm 8.4$ & 0.33 \\
Waist Circumference & $83.6 \pm 13.2$ & $84.6 \pm 16.5$ & 0.79 \\
(cm) & 19 & 12 & 0.38 \\
$\begin{array}{l}\text { Elevated Waist } \\
\text { Circumference (\%) }\end{array}$ & 36 & 37 & 0.89 \\
$\begin{array}{l}\text { On Medications (\%) } \\
\text { Positive Family }\end{array}$ & 34 & 44 & 0.012 \\
$\begin{array}{l}\text { History (\%) } \\
\text { Systolic Blood }\end{array}$ & $119 \pm 12$ & $153 \pm 20$ & $<0.001$ \\
$\begin{array}{l}\text { Pressure (mm Hg) } \\
\text { Diastolic Blood } \\
\text { Pressure (mm Hg) }\end{array}$ & $76 \pm 18$ & $96 \pm 14$ & $<0.001$ \\
\hline
\end{tabular}

On further analysis, waist circumference did not correlate with systolic $(p=0.74)$ or diastolic blood pressure $(p=0.46)$. On linear regression, waist circumference as a continuous variable was not an independent predictor of hypertension $(\mathrm{p}=0.78)$. Elevated waist circumference was not an independent predictor of hypertension $(\mathrm{p}=0.38)$ on logistic regression. Furthermore, age, sex, height, and use of any medications were not associated with hypertension. Finally, family history was an independent predictor of hypertension $(\mathrm{OR}=2.7, \mathrm{p}=0.013 ; 95 \% \mathrm{CI}, 1.2-5.8)$.

\section{Discussion}

The primary aim of this study was to discover the prevalence of hypertension in the agricultural workers residing in Batey 16. Compared to the reported rates in the literature, the prevalence of hypertension in Batey 16 residents (34\%) was slightly higher than in Dominicans $(28.4 \%)[8]$, but lower than in urban Haitians (46.5-48.7\%)[6]. Similarly, awareness of hypertensive status and treatment rates among those who were hypertensive in Batey $16(30 \%$ and $47 \%$, respectively) were considerably different than in the Dominican Republic as a whole $(80.6 \%$ and $84.8 \%$, respectively)[11] and in Haiti (39\% and $8 \%$, respectively)[12]. Furthermore, the prevalence of pre-hypertension in the Batey 16 population (42\%) was substantially higher than in urban Haitians (9.1-10.5\%)[6]. 
These findings suggest that both cultural and geographic factors can influence prevalence, awareness, and treatment of hypertension.

The prevalence of hypertension in Batey 16 residents could also be contributed to the migratory nature of the agricultural workers and the rural location of bateyes. Unfortunately, literature on hypertension in migrant workers is lacking and literature comparing hypertension in rural and urban populations is conflicting. Studies have found that an individual's country of residence, sex, and race are all variables that can influence rural or urban preponderance of hypertension [9,13-16]. Further, considering that the Dominican Republic is an upper-middle income country, rural residence should not affect hypertension awareness and treatment [9]. Interestingly, race in combination with either rural or urban residence has been shown to influence physician's recommendations and patient actions to control hypertension [17]. Due to the fact that literature on this topic is inconclusive, it is important to consider the possibility that rural or urban settings may influence blood pressure.

It is well established that a family history of hypertension is a risk factor for developing hypertension, especially at an earlier age [18-20]. It is therefore not surprising that we found an association between family history and hypertension. It is however, surprising that blood pressure was not correlated to age or waist circumference in our study sample. Literature has shown that individuals with elevated waist circumferences are at an increased risk of having elevated blood pressures [21-22]. This inconsistency may be explained by the population's relatively small average waist circumference. The low prevalence of elevated waist circumference is likely a result of a high level of physical fitness from performing frequent manual labor. A rise in blood pressure with age is also universally supported, except in select non-industrialized populations [20,23-24]. Even within these populations, studies that documented a lack of blood pressure increase with age have many limitations [23-24]. Based on the preliminary findings of these studies, the bateyes provide an ideal population to research the validity of literature documenting groups with no age-related rise in blood pressure. Understanding the factors responsible for this phenomenon may help control blood pressure in the elderly and related morbidity and mortality in the industrialized world.

The inconsistency between self-reported and measured hypertension is a problem that has been identified around the world [25-30]. We found that the batey population is no exception to this pattern. Although there are many proposed reasons for this discrepancy, in the Batey 16 population, a likely contributory factor is the extremely low rate of blood pressure screening and the resulting large number of individuals who have never had their blood pressures measured. Based on anecdotal evidence, low health literacy seemed to be another contributing factor. We observed that there was confusion between the phrases "high blood pressure" and "blood pressure a little above normal," which could have led to miscommunication between batey residents and their healthcare providers.

The protocol and conduction of our study is not without limitations. All individual blood pressures were measured in one visit, which is not as accurate as blood pressures measured over the course of multiple visits [31]. We tried to alleviate this issue by taking three separate blood pressure measurements, each at least one minute apart. Further, the 187 participants may not have been a complete representation of the Batey 16 population. This study was carried out from house to house, therefore any residents not present during our visits or that refused to participate were not included in the study. We are fairly confident that we included nearly all of the Batey 16 residents because care was taken to revisit houses whose residents were not present during the initial visit. This study was also carried out during the time of the year when workload was minimal for sugar cane harvesters so that most workers would be home. In addition, participant's weights were not measured in this study. Without weight measurements, we could not establish the obesity status in this population and therefore could not evaluate its impact on hypertension. Lastly, conducting the survey through a translator can cause misinterpretation of survey questions. We limited the misinterpretation by translating all survey questions into Spanish for the translators. We also worked with the translators to create predefined translations of the questions into Creole, ensuring that no content and meaning were lost.

Our study highlights the need for further research of the unique batey population. We have provided preliminary data on the prevalence, awareness, and treatment of hypertension in the Batey 16 population, but a larger study can confirm these patterns throughout all bateyes. We have also provided insight into potential risk factors that lead to an intermediate rate of hypertension between that of Dominicans and Haitians, but further clarification is needed. Much is still unknown about the patterns seen in self-reported and measured hypertension rates, the relationship between waist circumference and hypertension, and the relationship between age and hypertension in bateyes. It appears that there is still much more to be learned from this untapped resource.

\section{Conclusion}

Blood pressure screenings revealed that $34 \%$ of the Batey 16 population had hypertension and $42 \%$ had pre-hypertension. Age, sex, height, use of medication, and elevated waist circumference were not associated with hypertension and therefore do not appear to be risk factors in this population. The only independent predictor of hypertension was a family history of hypertension. More research needs to be conducted in order to gain insight into what specific characteristics of the batey environment and/or the Haitian-Dominican culture make this population unique. 


\section{Acknowledgements}

We are very grateful to the Meadowbrook Fund for supporting this project through the Hofstra North Shore-LIJ Summer Research Program Stipend and the Cohen's Children Medical Center of New York for establishing the Batey Outreach Program.

\section{References}

[1] Inter-American Commission on Human Rights. Report on the Situation of Human Rights in the Dominican Republic. Available http://www.cidh.org/countryrep/DominicanRep99/Table.htm. Accessed September 20, 2014.

[2] Simmons D. Structural violence as social practice: Haitian agricultural workers, anti-Haitianism, and health in the Dominican Republic. Hum Organ [serial online]. 2010;69 (1):10-18. Available from Health Reference Center Academic [database online] at: http://www.gale.cengage.com. Accessed December 26, 2013.

[3] Gwyther ME, Jenkins M. Migrant farmworker children Health status, barriers to care, and nursing innovations in health care delivery. J Pediatr Health Care [serial online]. 1998;12 (2):60-66. Available from Medline [database online] at: www.ebscohost.com. Accessed December 26, 2013.

[4] Lilly LS. Pathophysiology of Heart Disease. 5th ed. Philadelphia, Pa: Lippincott Williams \& Wilkins; 2010.

[5] World Health Organization. Q\&As on hypertension. Available at: http://www.who.int/features/qa/82/en/. Accessed December 26, 2013.

[6] Jean-Baptiste ED, Larco P, Charles-Larco N, Vilgrain C, Simon D, Charles R. Glucose intolerance and other cardiovascular risk factors in Haiti. Prevalence of Diabetes and Hypertension in Haiti (PREDIAH). Diabetes Metab [serial online]. 2006;32 (5):443-451. Available from Medline [database online] at: www.ebscohost.com. Accessed December 26, 2013.

[7] Centers for Disease Control and Prevention. Hypertension Among Adults in the United States: National Health and Nutrition Examination Survey, 2011-2012. Available at: http://www.cdc.gov/nchs/data/databriefs/db133.htm. Accessed December 26, 2013.

[8] Aono H, Ozawa H, Bello MC, Ito M, Saito I. Prevalence of risk factors for coronary heart disease among Dominicans in the Dominican Republic: comparison with Japanese and Americans using existing data. $J$ Epidemiol [serial online]. 1997;7 (4):238-243. Available from Medline [database online] at: www.ebscohost.com. Accessed December 26, 2013.

[9] Chow CK, Teo KK, Rangarajan S, et al. Prevalence, awareness, treatment, and control of hypertension in rural and urban communities in high-, middle-, and low-income countries. JAMA [serial online]. September 2013;310 (9):959-968. Available from: The JAMA Network, Chicago, Il. Accessed December 26, 2013.

[10] National Heart, Lung, and Blood Institute. According to Waist Circumference. Available at: http://www.nhlbi.nih.gov/guidelines/obesity/e_txtbk/txgd/41 42.htm. Accessed September 5, 2013.

[11] Prince MJ, Ebrahim S, Acosta D, et al. Hypertension prevalence, awareness, treatment and control among older people in Latin America, India and China: a 10/66 cross-sectional population-based survey. J Hypertens [serial online]. 2012;30 (1):177-187. Available from Web of Knowledge [database online] at: apps.webofknowledge.com. Accessed December 29, 2013.

[12] Shipp ML. Awareness status and prevalence of hypertension in a group of urban Haitians: findings of a population-based survey. Ethn Dis [serial online]. 2001;11 (3):419-430. Available from Medline [database online] at: www.ebscohost.com. Accessed December 29, 2013.

[13] Mainous AG, King DE, Garr DR, Pearson WS. Race, rural residence, and control of diabetes and hypertension. Ann Fam Med [serial online]. 2004;2 (6):563-568. Available from Medline [database online] at: www.ebscohost.com. Accessed December 26, 2013.

[14] Campos H, Mata L, Siles X, Vives M, Ordovas JM, Schaefer EJ. Prevalence of cardiovascular risk factors in rural and urban Costa Rica. Circulation [serial online]. 1992;85 (2):648-658. Available from Medline [database online] at: www.ebscohost.com. Accessed December 29, 2013.

[15] Addo J, Smeeth L, Leon DA. Hypertension in sub-saharan Africa: a systematic review. Hypertension [serial online]. 2007;50 (6):1012-1018. Available from Google Scholar [database online] at: scholar.google.com. Accessed December 29, 2013.

[16] Mbanya JC, Minkoulou EM, Salah JN, Balkau B. The prevalence of hypertension in rural and urban Cameroon. Int J Epidemiol [serial online]. 1998;27 (2):181-185. Available from Google Scholar [database online] at: scholar.google.com. Accessed December 29, 2013.

[17] Ellis C, Grubaugh AL, Egede LE. The effect of minority status and rural residence on actions to control high blood pressure in the U.S. Public Health Rep [serial online]. 2010;125 (6):801-809. Available from Medline [database online] at: www.ebscohost.com. Accessed December 29, 2013.

[18] Chen X, Zhang ZX, George LK, et al. Birth measurements, family history, and environmental factors associated with later-life hypertensive status. Am J Hypertens [serial online]. 2012;25 (4):464-471. Available from Medline [database online] at: www.ebscohost.com. Accessed December 29, 2013.

[19] Barksdale DJ, Metiko E. The role of parental history of hypertension in predicting hypertension risk factors in Black Americans. J Transcult Nurs [serial online]. 2010;21 (4):306-313. Available from Medline [database online] at: www.ebscohost.com. Accessed December 29, 2013.

[20] Longo DL, Fauci AS, Kasper DL, Hauser SL, Jameson JL, Loscalzo J, eds. Harrison's Principles of Internal Medicine. 18th ed. New York, Ny: The McGraw-Hill Companies, Inc; 2011.

[21] Abbasi F, Blasey C, Reaven GM. Cardiometabolic risk factors and obesity: does it matter whether BMI or waist circumference is the index of obesity? Am J Clin Nutr [serial online]. 2013;98 (3):637-640. Available from Web of Knowledge [database online] at: apps.webofknowledge.com. Accessed December 29, 2013. 
[22] Ying-Xiu Z, Da-Yong S, Jing-Yang Z, Jin-Shan Z, Zun-Hua C. Blood pressure among children and adolescents with normal weight but large waist circumference in Shandong, China. Eur J Pediatr [serial online]. 2014;173 (3):285-289. Available from Medline [database online] at: www.ebscohost.com. Accessed December 29, 2013.

[23] Gurven M, Blackwell AD, Rodríguez DE, Stieglitz J, Kaplan H. Does blood pressure inevitably rise with age? longitudinal evidence among forager-horticulturalists. Hypertension [serial online]. 2012;60 (1):25-33. Available from Medline [database online] at: www.ebscohost.com. Accessed December 29, 2013.

[24] Stevenson DR. Blood pressure and age in cross-cultural perspective. Hum Biol [serial online]. 1999;71 (4):529-551. Available from Medline [database online] at: www.ebscohost.com. Accessed December 29, 2013.

[25] Atwood KM, Robitaille CJ, Reimer K, Dai S, Johansen HL, Smith MJ. Comparison of diagnosed, self-reported, and physically-measured hypertension in Canada. Can J Cardiol [serial online]. 2013;29 (5):606-612. Available from Medline [database online] at: www.ebscohost.com. Accessed December 29, 2013.

[26] Taylor A, Dal Grande E, Gill T, et al. Comparing self-reported and measured high blood pressure and high cholesterol status using data from a large representative cohort study. Aust $N Z J$ Public Health [serial online]. 2010;34 (4):394-400. Available from Web of Knowledge [database online] at: apps.webofknowledge.com. Accessed December 29, 2013.

[27] Dave GJ, Bibeau DL, Schulz MR, et al. Predictors of congruency between self-reported hypertension status and measured blood pressure in the stroke belt. $J$ Am Soc Hypertens [serial online]. 2013;7 (5):370-378. Available from Medline [database online] at: www.ebscohost.com. Accessed December 29, 2013.

[28] Mentz G, Schulz AJ, Mukherjee B, Ragunathan TE, Perkins DW, Israel BA. Hypertension: development of a prediction model to adjust self-reported hypertension prevalence at the community level. BMC Health Serv Res [serial online]. 2012;12:312. Available from Medline [database online] at: www.ebscohost.com. Accessed December 29, 2013.

[29] Tsai AC, Chang TL. Quality issues of self-report of hypertension: analysis of a population representative sample of older adults in Taiwan. Arch Gerontol Geriatr [serial online]. 2011;55 (2):338-342. Available from Medline [database online] at: www.ebscohost.com. Accessed December 29, 2013.

[30] White K, Avendaño M, Capistrant BD, Moon JR, Liu SY, Glymour MM. Self-reported and measured hypertension among older US- and foreign-born adults. J Immigr Minor Health [serial online]. 2012;14 (4):721-726. Available from Medline [database online] at: www.ebscohost.com. Accessed December 29, 2013.

[31] Pickering TG, Hall JE, Appel LJ, et al. Recommendations for blood pressure measurement in humans and experimental animals: part 1: blood pressure measurement in humans: a statement for professionals from the Subcommittee of Professional and Public Education of the American Heart Association Council on High Blood Pressure Research. Circulation [serial online]. 2005;111 (5):697-716. Available from Google Scholar [database online] at: scholar.google.com. Accessed December 29, 2013. 